ISSN: 1410-8917

Jurnal Kimia - Sains \& Aplikasi

e-ISSN: 2597-9914

\section{Jurnal Kimia Sains dan Aplikasi} Journal of Scientific and Applied Chemistry

Journal homepage: http://ejournal.undip.ac.id/index.php/ksa

\title{
Validation of UV-VIS Spectrophotometric Methods for Determination of Inulin Levels from Lesser Yam (Dioscorea esculenta
}

\section{L.)}

\author{
Sandra Ayu Apriliyani ${ }^{\mathrm{a}}$, Yohanes Martono ${ }^{\mathrm{a}}{ }^{*}$, Cucun Alep Riyanto ${ }^{\mathrm{a}}$, Mutmainah $^{\mathrm{b}}$, dan Lia \\ Kusmita ${ }^{\mathrm{b}}$ \\ a Program Studi Kimia, Fakultas Sains dan Matematika, Universitas Kristen Satya Wacana, Salatiga, 50711, Indonesia \\ b Sekolah Tinggi Ilmu Farmasi "Yayasan Pharmasi", Semarang, Indonesia \\ * Corresponding author: yohanes.martono@staff.uksw.edu \\ https://doi.org/10.14710/jksa.21.4.161-165
}

\begin{tabular}{l} 
Article Info \\
\hline Article history: \\
Received: 9 July 2018 \\
Revised: 6 August 2018 \\
Accepted: 9 August \\
2018 \\
Online: 31 October 2018 \\
\hline Keywords: \\
yam (Dioscorea \\
esculenta L.), inulin, \\
UV-Vis \\
spectrophotometry, \\
validation method
\end{tabular}

\begin{tabular}{l}
\hline \\
\hline Kata Kunci: \\
gembili (Dioscorea \\
esculenta L.), inulin, \\
spektrofotometer UV- \\
Vis, validasi metode
\end{tabular}

\section{Abstract}

Validation of methods is necessary to ensure that the analytical methods used are appropriate and reliable. In this research, the determination of validation method and determination of inulin content from gembili bulb (Dioscorea esculenta L.). The method used for determining inulin levels is UV-Vis spectrophotometry. Based on the results obtained, the maximum wavelength determination of inulin levels is $520 \mathrm{~nm}$. The method of analysis in this study meets the specified validation requirements. These parameters include the equation on the inulin raw curve $y=0.0045 \mathrm{x}+0.109$ with the coefficient of determination 0.9992 . The accuracy of the methods tested using the recovery test was $96.14-106.76 \%$ at concentrations of 25,100 , and $225 \mathrm{ppm}$. The intraday precision test is in the range of $2.67-6.82 \%$ at the same concentration as the accuracy test. Precision interday equal to $7.41 \%$ at concentration $225 \mathrm{ppm}$ for 3 day analysis period. The values of LOD and LOQ are $3.58 \mathrm{ppm}$ and $11.95 \mathrm{ppm}$, respectively. The concentration of inulin extract from gembili bulb is $840.44-12188.59 \mathrm{ppm}$.

\section{Abstrak}

Validasi metode perlu dilakukan untuk menjamin bahwa metode analisis yang digunakan sudah sesuai dan dapat diandalkan. Pada penelitian ini dilakukan penentuan validasi metode dan penetapan kadar inulin dari umbi gembili (Dioscorea esculenta L.). Metode yang digunakan untuk penetapan kadar inulin adalah spektrofotometri UV-Vis. Berdasarkan hasil yang diperoleh, panjang gelombang maksimum penetapan kadar inulin adalah $520 \mathrm{~nm}$. Metode analisis pada penelitian ini memenuhi persyaratan validasi yang ditentukan. Parameter tersebut meliputi persamaan pada kurva baku inulin $\mathrm{y}=0,0045 \mathrm{x}+0,1009$ dengan koefisien determinasi 0,9992 . Akurasi metode yang diuji menggunakan tes recovery adalah $96,14-106,76 \%$ pada konsentrasi 25,100 , dan 225 ppm. Uji presisi intraday pada kisaran 2,67-6,82\% pada konsentrasi yang sama dengan uji akurasi. Presisi interday sebesar 7,41\% pada konsentrasi $225 \mathrm{ppm}$ untuk periode analisis 3 hari. Nilai LOD dan LOQ adalah 3,58 ppm dan 11,95 ppm, secara berurutan. Konsentrasi ekstrak inulin dari umbi gembili adalah sebesar 840,44$12188,59 \mathrm{ppm}$. 


\section{Pendahuluan}

Inulin merupakan polimer alami yang dapat digolongkan sebagai oligo- atau polisakarida berdasarkan panjang rantainya dan termasuk fruktan dalam kelompok karbohidrat [1]. Menurut Temkov $d k k$. [2], inulin terdiri dari monomer D-fruktosa yang dihubungkan dengan ikatan $\beta(2 \rightarrow 1)$ dan diakhiri dengan residu D-glukosa yang dihubungkan dengan D-fruktosa melalui ikatan $\alpha(1 \rightarrow 2)$. Sebagai bahan pangan fungsional, inulin banyak dimanfaatkan sebagai pengganti gula \& lemak yang memiliki nilai kalori rendah.

Inulin terdapat dalam beberapa jenis umbi-umbian, salah satunya adalah gembili. Gembili merupakan tanaman merambat dengan daun berbentuk ginjal berwarna hijau dan memiliki batang yang berduri, umbi gembili memiliki warna kulit coklat dan warna dagingnya adalah putih. Berdasarkan penelitian yang pernah dilakukan pada beberapa umbi-umbian yang ada di Indonesia, umbi gembili merupakan umbi yang paling banyak mengandung inulin yaitu mencapai 14,77\%[3].

Penetapan kadar inulin dapat dilakukan dengan beberapa metode analisis seperti penelitian Nisa $d k k$. [4] yang melakukan penetapan kadar inulin dalam ekstrak umbi dahlia menggunakan metode KLT densitometri. Di Venere $d k k$. [5] juga melakukan penetapan kadar inulin namun menggunakan metode HPLC. Metode lain yaitu secara spektrofotometri, kelebihan dari metode ini adalah sederhana, lebih cepat dalam pelaksanaannya, dan cocok digunakan untuk analisis rutin laboratorium sehingga secara keseluruhan metode spektrofotometri lebih efisien dibandingkan metode lain seperti kromatografi [6]. Namun demikian, beberapa penelitian tentang penetapan kadar inulin secara spektrofotometri belum melakukan validasi metode salah satunya adalah penelitian Iskandar dkk yang melakukan penetapan kadar inulin dari ekstrak umbi dahlia secara spektrofotometri [7].

Validasi metode sangat diperlukan untuk menjamin metode analisis yang digunakan memberikan data yang valid dan dapat diandalkan. Menurut Muharrami [8], validasi metode adalah serangkaian seri percobaan yang digunakan untuk memastikan metode analisis yang akan dipakai telah memenuhi persyaratan yang ditentukan. Validasi metode merupakan hal yang penting untuk dilakukan karena digunakan sebagai jaminan suatu pengukuran dapat diandalkan [9]. Berdasarkan latar belakang yang ada, maka tujuan dari penelitian ini adalah untuk menentukan validasi metode dan penetapan kadar inulin dari umbi gembili menggunakan metode spektrofotometri.

\section{Metodologi}

\section{Alat dan Bahan}

Bahan yang digunakan dalam penelitian ini adalah inulin standar (Sigma-aldrich, Germany), vanilin standar (Merck, Germany), akuades, dan asam sulfat $98 \%$. Semua bahan kimia yang digunakan berderajat pro analisis. Alat yang digunakan dalam penelitian ini diantaranya adalah neraca analitik dengan ketelitian 0,1 mg (OHAUS PA214), spektrofotometer UV-Vis (SHIMADZU 1240), kuvet plastik, vorteks, dan peralatan gelas laboratorium.

\section{Metode}

\section{Pembuatan Reagen Vanilin [10].}

Seberat $1,52 \mathrm{~g}$ vanilin dilarutkan dalam $200 \mathrm{~mL}$ asam sulfat $98 \%$ hingga homogen, larutan ini akan digunakan sebagai reagen dalam pengukuran selanjutnya.

\section{Penentuan Panjang Gelombang Maksimum [10]}

Penentuan panjang gelombang maksimum inulin standar dilakukan dengan cara pemindaian (scanning) pada panjang gelombang 200-700 $\mathrm{nm}$ dengan blanko akuades.

\section{Pembuatan Kurva Baku Inulin [10] dan Uji Linieritas [11]}

Larutan standar inulin dibuat dalam konsentrasi 10$350 \mathrm{mg} / \mathrm{L}$ kemudian ditambahkan reagen vanilin dengan perbandingan 1:1 dan didiamkan selama 15 menit. Absorbansi seri larutan standar diukur menggunakan spektrofotometer UV-Vis pada panjang gelombang maksimum. Hasil absorbansi diplotkan dalam bentuk kurva kemudian dibuat suatu persamaan garis regresi linear dan ditentukan koefisien determinasinya.

\section{Akurasi [12].}

Akurasi dilakukan dengan pengukuran 3 konsentrasi larutan standar $(25,200$, dan $225 \mathrm{mg} / \mathrm{L})$ yang masingmasing dibuat secara triplo, pengukuran dilakukan menggunakan spektrofotometri UV-VIS. Nilai trueness dari hasil pengukuran dihitung dengan rumus:

$$
\text { nilai trueness }=\frac{\text { kadar } u \text { kur }}{\text { kadar teoritis }} \times 100 \%
$$

\section{Presisi [13]}

Presisi intraday dilakukan dengan menghitung nilai RSD hasil pengukuran 3 konsentrasi larutan yang masing-masing dibuat secara triplo dalam hari yang sama. Presisi interday dilakukan dengan menghitung nilai RSD dari 1 konsentrasi larutan yang diulang pembuatannya selama 3 hari berturut-turut. Nilai RSD dihitung dengan rumus:

$R S D=\frac{S D}{\text { konsentrasi terukur }} \times 100 \%$ 


\section{Batas Deteksi (LOD) dan Batas Kuantitasi (LOO) [14]}

Pembuatan blanko diulang minimal 10 kali dan dilakukan pengukuran menggunakan spektrofotometer UV-Vis. Hasil absorbansi kemudian dimasukkan ke dalam rumus:

$L O D=\frac{3 \times S D \text { blanko }}{\text { slope }}$

$L O D=\frac{10 \times S D \text { blanko }}{\text { slope }}$

\section{Analisa Sampel [10]}

Ekstrak inulin dari umbi gembili ditambah dengan reagen vanilin dengan perbandingan 1:1 kemudian didiamkan selama 15 menit. Pengukuran dilakukan menggunakan spektrofotometer UV-Vis pada panjang gelombang maksimum. Konsentrasi inulin dihitung berdasarkan kurva baku.

\section{Hasil dan Pembahasan}

Penentuan Panjang Gelombang Maksimum.

Panjang gelombang maksimum merupakan panjang gelombang di mana terjadi eksitasi elektronik yang memberikan absorbansi maksimum. Pengukuran dilakukan pada panjang gelombang maksimum karena pada panjang gelombang maksimum perubahan absorbansi untuk setiap satuan konsentrasi paling besar, sehingga akan diperoleh kepekaan analisis yang maksimum [15]. Berdasarkan hasil pemindaian, panjang gelombang maksimum inulin yang diperoleh yaitu 520 $\mathrm{nm}$, ditunjukkan pada Gambar 1. Hasil yang didapat sejalan dengan penelitian Dobre [16] yang menyatakan bahwa inulin membentuk kompleks berwarna merah tua ketika direaksikan reagen vanilin dan memiliki karakteristik dalam spektrum serapan $520 \mathrm{~nm}$.

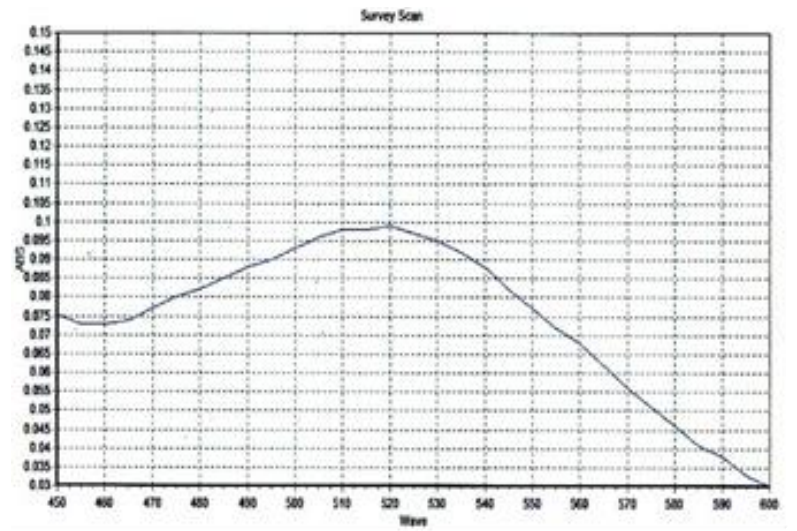

Gambar 1. Panjang Gelombang Maksimum Inulin

\section{Kurva Baku Inulin dan Uji Linieritas.}

Uji linieritas dilakukan untuk mengetahui kemampuan standar sehingga adanya hubungan linier antara konsentrasi analit dengan respon detektor dapat diketahui [17]. Berdasarkan hasil yang diperoleh, ada 3 kurva baku inulin yang dihasilkan pada penelitian ini dengan persamaan masing-masing yang dapat dilihat pada Tabel 1. Kurva baku terpilih yaitu kurva baku ke-3 yang dengan persamaan $y=0,0045 x+0,1009$ dan koefisien determinasi sebesar 0,9992 yang dapat dilihat pada Gambar 2. Kurva baku ke-3 ditetapkan sebagai kurva baku inulin pada penelitian ini karena memiliki linieritas yang baik. Menurut Chan dalam Riyanto [9], koefisien determinasi yang dihasilkan sudah sesuai dan dapat diterima karena nilai yang dihasilkan mendekati 1 dan $>0,9970$.

Tabel 1. Persamaan Kurva Baku Inulin

\begin{tabular}{|c|c|c|}
\hline Kurva & Persamaan & $\begin{array}{c}\text { Koefisien } \\
\text { Determinasi }\end{array}$ \\
\hline 1 & $y=0,0045 x+0,0879$ & 0,9982 \\
\hline 2 & $y=0,0045 x+0,1045$ & 0,9981 \\
\hline 3 & $y=0,0045 x+0,1009$ & 0,9992 \\
\hline 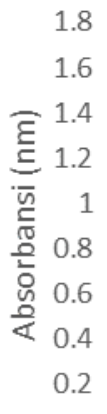 & $\begin{array}{r}y=0.0045 x+ \\
R^{2}=0.99\end{array}$ & 09 \\
\hline & 100 & 400 \\
\hline & Konsentra & \\
\hline
\end{tabular}

Gambar 2. Kurva Baku Inulin

Akurasi.

Akurasi merupakan ukuran yang menunjukkan kedekatan hasil analisis dengan kadar analit yang sebenarnya dan dinyatakan sebagai persen perolehan kembali atau persen recovery [14]. Pada penelitian ini akurasi dinyatakan dalam nilai trueness karena metode yang digunakan adalah pengukuran standar. Dari hasil perhitungan, nilai trueness yang didapatkan berada pada range 96,14-106,76\% (Tabel 2). Hasil perhitungan ini memenuhi syarat karena untuk larutan dengan konsentrasi $\geq 10 \mu \mathrm{g} / \mathrm{mL}$ nilai trueness berkisar $80-100 \%$ dan untuk larutan dengan konsentrasi $\geq 100 \mu \mathrm{g} / \mathrm{mL}$ nilai trueness berkisar 90-107\% [12]. Dengan demikian hasil uji akurasi yang diperoleh pada penelitian ini dapat diterima.

Tabel 2. Hasil Perhitungan Akurasi

\begin{tabular}{cccc}
\hline Konsentrasi & 25 & 100 & 225 \\
\hline Nilai trueness & 106,76 & 106,69 & 96,14 \\
\hline
\end{tabular}


Presisi.

Menurut Chandra dkk. [11], presisi merupakan ukuran yang menunjukkan kedekatakan hasil analisis apabila pengukuran dilakukan oleh analis yang sama dengan waktu yang berbeda. Hasil uji presisi intraday yang telah dilakukan disajikan pada Tabel 3.

Tabel 3. Hasil Uji Presisi

\begin{tabular}{cccc}
\hline \multicolumn{5}{c}{ Intraday } \\
\hline $\begin{array}{c}\text { Konsentrasi } \\
\text { Teoritis }\end{array}$ & $\begin{array}{c}\text { Rata-Rata } \\
\text { Konsentrasi } \\
\text { Terukur }\end{array}$ & SD & $\begin{array}{c}\text { RSD } \\
(\%)\end{array}$ \\
\hline 25 & 26,69 & 1,82 & 6,82 \\
100 & 106,69 & 4,08 & 3,82 \\
225 & 216,32 & 5,77 & 2,67 \\
\hline \multicolumn{5}{c}{ Interday } \\
Teoritis & Konsentrasi \\
& Terukur & SD & RSD \\
\hline 225 & 226,25 & 16,77 & 7,41 \\
\hline
\end{tabular}

Berdasarkan hasil perhitungan presisi pada penelitian ini, hasil yang diperoleh sudah sesuai dengan standar yang ada dan dapat diterima karena dalam satuan ppm, presisi dapat diterima jika memiliki nilai RSD $\pm 16 \%$ [9]. Selain itu karena hasil pada uji presisi memiliki nilai RSD lebih dari $2 \%$ maka dilakukan perbandingan dengan koefisien variasi Horwitz. Hasil yang diperoleh dari perbandingan ini menunjukkan bahwa nilai RSD lebih kecil dari koefisien variasi Horwitz oleh karena itu hasil dapat diterima dan dinyatakan presisi.

\section{Batas Deteksi (LOD) dan Batas Kuantitasi (LOO).}

Batas deteksi adalah jumlah terkecil analit dalam sampel yang dapat dideteksi dan masih memberikan respon signifikan dibandingkan dengan blanko, sedangkan batas kuantitasi adalah kuantitas terkecil analit dalam sampel yang masih dapat memenuhi kriteria cermat dan seksama[13]. Berdasarkan hasil yang diperoleh, nilai LOD sebesar 3,58 ppm dan LOQ sebesar 11,95 ppm. Hal ini menunjukkan bahwa pada konsentrasi 3,58 ppm masih dapat dilakukan mendeteksi sampel yang memberikan hasil ketelitian suatu alat berdasarkan tingkat akurasi individual hasil analisis dan apabila dilakukan pengukuran, pada konsentrasi 11,95 ppm masih dapat memberikan kecermatan analisis [18].

\section{Analisa Sampel.}

Konsentrasi ekstrak inulin dari umbi gembili didapatkan dengan memplotkan hasil absorbansi ke dalam persamaan pada kurva baku dan dikalikan dengan faktor pengenceran, hasil dapat dilihat pada Tabel 4. Dari pengukuran ini, hasil yang diperoleh melebihi nilai LOQ sehingga konsentrasi ekstrak inulin masih dapat dideteksi oleh metode analisis.
Tabel 4. Konsentrasi Ekstrak Inulin $(n=3,00)$

\begin{tabular}{cc}
\hline Sampel & Konsentrasi $(\mathrm{mg} / \mathrm{Kg}) \pm \mathrm{SD}$ \\
\hline 1 & $258,22 \pm 0,0200$ \\
2 & $1511,11 \pm 0,0167$ \\
3 & $3129,33 \pm 0,0062$ \\
\hline
\end{tabular}

Keterangan: sampel 1 = ekstrak air Gembili secara maserasi. Sampel 2 = ekstrak air Gembili secara maserasi. Sampel 3 = ekstrak terpurifikasi Gembili

\section{Kesimpulan}

Dari hasil penelitian ini diperoleh panjang gelombang maksimum penetapan kadar inulin adalah $520 \mathrm{~nm}$. Metode analisis penelitian ini memenuhi persyaratan validasi yang ditentukan. Parameter tersebut meliputi persamaan pada kurva baku inulin $y=0,0045 x+$ 0,1009 dengan koefisien determinasi 0,9992. Akurasi metode yang diuji menggunakan tes recovery adalah 96,14-106,76 \% pada konsentrasi 25, 100, 225 ppm. Uji presisi intraday pada kisaran $2,67-6,82 \%$ pada konsentrasi yang sama dengan uji akurasi. Presisi interday sebesar 7,4104\% pada konsentrasi 225 ppm untuk periode analisis 3 hari. Nilai LOD dan LOQ adalah 3,5839 ppm dan 11,9464 ppm, secara berurutan. Konsentrasi ekstrak inulin dari umbi gembili adalah sebesar 840,44-12188,59 ppm.

\section{Ucapan Terima Kasih}

Peneliti mengucapkan terimakasih dan penghargaan kepada Kementrian Riset, Teknologi dan Pendidikan Tinggi yang telah mendanai penelitian ini melalui Hibah Penelitian Kerja Sama Perguruan Tinggi (PKPT) tahun anggaran 2017 pendanaan 2018 dan Universitas Kristen Satya Wacana (UKSW) yang telah memfasilitasi publikasi ilmiah ini.

\section{Referensi}

[1] Maarten A. Mensink, Henderik W. Frijlink, Kees van der Voort Maarschalk, Wouter L. J. Hinrichs, Inulin, a flexible oligosaccharide I: Review of its physicochemical characteristics, Carbohydrate Polymers, 130, (2015) 405-419 https://doi.org/10.1016/i.carbpol.2015.05.026

[2] Mishela Temkov, Nadezhda Petkova, Panteley Denev, Albert Krastanov, Characterization of inulin from Helianthus tuberosus L. obtained by different extraction methods - Comparative study, Food Science, Engineering and Technology 2015, Plovdiv, Bulgaria, (2015).

[3] Sri Winarti, Eni Harmayani, Rudi Nurismanto, Karakteristik dan Profil Inulin Beberapa Jenis Uwi (Dioscorea spp.), Agritech, 31, 4, (2012) 378-383 https://doi.org/10.22146/agritech.9647

[4] Khoirun Nisa, Yuni Retnaningtyas, Nia Kristiningrum, Penetapan Kadar Inulin dalam Ekstrak Umbi Dahlia variabilis dan Dahlia pinnata dengan Metode KLT Densitometri (Determination of Inulin Content in Dahlia variabilis and Dahlia pinnata 
Tuber Extract by TLC Densitometry Method), Pustaka Kesehatan, 3, 2, (2015) 284-288

[5] D. Di Venere, V. Linsalata, B. Pace, V.V. Bianca, P. Perrino, Polyphenol and Inulin Content in a Collection of Artichoke, ISHS Acta Horticulturae 681: IV International Congress on Artichoke, 681, (2005) 453460

http://dx.doi.org/10.17660/ActaHortic.2005.681.63

[6] Nadezhda Petkova, Panteley Denev, Methods for determination of inulin, Monograph of $4 \mathrm{rd}$ European young engineers conference, (2015).

[7] Yetti Mulyati Iskandar, Sri Pudjiraharti, Diah Ratnaningrum, Kandungan Inulin dari Umbi Dahliasp yang Ditanam pada Jenis Tanah Vertisol, Inceptisol dan Andisol, Jurnal Kimia Terapan Indonesia, 16, 1, (2014) 25-41 https://doi.org/10.14203/jkti.v16i1.5

[8] Laila Khamsatul Muharrami, Penentuan Kadar Kolesterol dengan Metode Kromatografi Gas, Agrointek, 12, 2, 28-32

[9] Riyanto, Validasi Dan Verifikasi Metode Uji, Deepublish, Yogyakarta, 2014.

[10] Wasan Omar Noori, Selection of Optimal Conditions of Inulin Extraction from Jerusalem Artichoke (Helianthus Tuberosus L.) Tubers by using Ultrasonic Water Bath, Journal of Engineering, 20, 10, (2014) 110119

[11] Boy Chandra, Harrizul Rivai, Marianis Marianis, Pengembangan Dan Validasi Metode Analisis Ranitidin Hidroklorida Tablet Dengan Metode Absorbansi Dan Luas Daerah Di Bawah Kurva Secara Spektrofotometri Ultraviolet, Jurnal Farmasi Higea, 8, 2, (2016)

[12] B. Nugraheni, A. B Anggoro, Validasi Metode Analisis Ciprofloksasin Menggunakan High Performance Liquid Chromatography, Inovasi Teknik Kimia, 1, 1, (2016) 6-8

[13] Yandi Syukri, Agung Endro Nugroho, Ronny Martien, Endang Lukitaningsih, Validasi Penetapan Kadar Isolat Andrografolid dari Tanaman Sambiloto (Andrographis paniculata Nees) Menggunakan HPLC, Jurnal Sains Farmasi \& Klinis 2, 1, (2015) 8-14 http://dx.doi.org/10.25077/jsfk.2.1.8-14.2015

[14] Harmita Harmita, Petunjuk Pelaksanaan Validasi Metode dan Cara Perhitungannya, Pharmaceutical Sciences and Research (PSR), 1, 3, (2012) 117-135 http://dx.doi.org/10.7454/psr.v1i3.3375

[15] Wiranti Sri Rahayu Rahayu, Pri Iswati Utami, Sochib Ibnu Fajar, Penetapan Kadar Tablet Ranitidin Menggunakan Metode Spektrofotometri Uv-Vis dengan Pelarut Metanol, Pharmacy, 6, 3, (2009) 104125 http://dx.doi.org/10.30595/pji.v6i3.881

[16] T Dobre, M Stroescu, A Stoica, E Draghici, N Antohe, Inulin extraction and encapsulation, Chem. Bull. "POLITEHNICA" Univ. (Timişoara), 53, 67, (2008) 215217

[17] Laras Andria Wardani, Validasi Metode Analisis dan Penentuan Kadar Vitamin C pada Minuman Buah Kemasan dengan Spektrofotometri Uv-Visible,
Departemen Kimia, Skripsi. Depok: Universitas Indonesia, Depok

[18] Grace Pricilia Tulandi, Sri Sudewi, Widya Astuty Lolo, Validasi Metode Analisis untuk Penetapan Kadar Parasetamol dalam Sediaan Tablet Secara Spektrofotometri Ultraviolet, PHARMACON, Jurnal Ilmiah Farmasi 4, 4, (2015) 168-178 